\title{
Influence of Hybrid Nano-Particles on Properties of Cement Mortar
}

\author{
Jagan Sivamani, Neelakantan T R
}

\begin{abstract}
Development of voids is one among the important properties that deprive the strength and durability of cement concrete. Voids not only been developed between heterogeneous ingredients of concrete but as well among the homogenous ingredients due to improper compaction and poor quality of materials etc. In this study, an attempt has been taken to study the effect of reduction in voids among the homogenous materials on strength properties of cement mortar. To counteract formation of voids, a Nano-material (Ceric Ammonium Nitrate $\mathrm{H}_{8} \mathrm{~N}_{8} \mathrm{CeO} \mathrm{O}_{18}$ ) is being loaded over another Nano-material (Silica $\mathrm{SiO}_{2}$ ) each having different properties to act as a single Hybrid Nanomaterial $(H N)$. Pore volume analysis, Infra-red test, and SEM analysis were performed to study the properties of $\mathrm{HN}$. On the other hand, various tests like setting time, compressive strength and split tensile strength were performed on cement mortar specimens upon addition of $\mathrm{HN}$ by 3\%, 5\%, 7\% and $10 \%$ by weight of cement. Results reveal that strength of mortar with $\mathrm{HN}$ is higher compared to mortar with Nano silica as well as conventional cement mortar specimens.
\end{abstract}

Keywords: Ceric Ammonium Nitrate, Hybrid Nano material, Pore Volume Analysis, Silica, SEM and Infrared test

\section{INTRODUCTION}

Cement mortar is a building compound which is highly susceptible to entry of chemicals or any other harmful substances if it possesses any voids in it due to improper compaction. It has been mandated to utilize alternative additive materials whose size is in the order less than that of the ingredients of mortar. Under current scenario various researches have been conducted to utilize Nano-materials (size of $1 \times 10^{-9}$ to $100 \times 10^{-9} \mathrm{~m}$ ) to achieve some unique properties. Various Nano- materials used in the previous study that decreased the porosity in concrete include Nano- $\mathrm{SiO}_{2}, \quad \mathrm{TiO}_{2}, \quad \mathrm{Al}_{2} \mathrm{O}_{3}$ and $\mathrm{Fe}_{2} \mathrm{O}_{3} \quad$ [1]. Other Nano-materials like carbon Nano-tubes are efficient in reducing the porosity and improving the ductility property [2, 3, 4 and 5]. Similarly Nano- $\mathrm{TiO}_{2}$ accelerates the hydration of cement at early ages, promotes the pozzolanic reaction in addition with supplementary cementitious materials and formation of longer $\mathrm{C}-\mathrm{S}-\mathrm{H}$ chain [6]. On the other hand Nano-techniques in clay particles also activate the process of hydration by forming additional hydration products. This in turns improves the compressive strength and bulk density [7]. If the clay particles contains montmorillonite mineral in it, mechanical properties like compressive strength, split tensile strength and flexural strength gets increased due to the acceleration of hydration through nucleation effect [8]. Under elevated temperatures, Nano-materials evident a decrease in the compressive strength and flexural strength beyond $250^{\circ} \mathrm{C}$, which is due to the development of micro and macro cracks at higher temperatures [9]. Addition of $\mathrm{Nano}-\mathrm{SiO}_{2}$ in cement mortar improves the strength of cement mortar by promoting the pozzolanic reaction i.e. through the reaction with calcium hydroxide. [10]. Nano- $\mathrm{SiO}_{2}$ reduces the setting time of cement as more water is required when more $\mathrm{SiO}_{2}$ was added [11]. With respect to durability, Nano- $\mathrm{SiO}_{2}$ increases the super plasticizer demand of mortar and significantly increases the strength and improves the durability properties of mortar. This is due to the pore filling property with higher particle density [12]. On comparison with the properties of various Nano-materials, Nano- $\mathrm{SiO}_{2}$ (NS) found to be more precise in its behaviour. Our research focuses on utilization of hybrid Nano-materials prepared by conglomeration of Nano- $\mathrm{SiO}_{2}$ (NS) and Ceric Ammonium Nitrate $\mathrm{H}_{8} \mathrm{~N}_{8} \mathrm{CeO}_{18}$ as an additive to improve the properties in cement mortar. In this study, Hybrid Nanomaterial (HN) is added at percentages of $3 \%, 5 \%, 7 \%$ and $10 \%$ by weight of cement. Various property tests on HN such as Pore Volume analysis, Infra-red analysis and Micro-structural analysis were examined and mechanical properties on cement mortar were also analyzed on cement mortar upon addition of $\mathrm{HN}$.

\section{METHODOLOGY}

\section{A. Materials}

OPC of 33 grades, fine aggregate passing through 2.36mm sieve with fineness modulus 2.7, Ceric Ammonium Nitrate $\mathrm{H}_{8} \mathrm{~N}_{8} \mathrm{CeO}_{18}$ and $\mathrm{Nano}-\mathrm{SiO}_{2}$ (NS) as hybrid Nano-material and water conforming to IS 456:2000 were used as ingredients for the preparation of mortar. Properties of Ingredients used in this study was tested and presented in table I. Email: s.jagan@klu.ac.in

T.R. Neelakantan, Civil Engineering Department, Kalasalingam Academy of Research and Education, Krishnankoil, India. Email: neelakantan@klu.ac.in

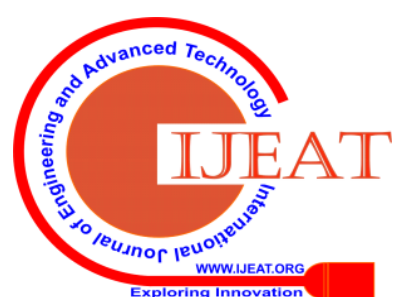


Table- I: Properties of Ingredients

\begin{tabular}{|c|c|c|c|}
\hline \multirow{2}{*}{ S. No } & \multirow{2}{*}{ Properties } & \multicolumn{2}{|c|}{ Values } \\
\cline { 3 - 4 } & & Nano Silica & Nano cerium \\
\hline 1 & Density & $2.4 \mathrm{~g} / \mathrm{cm}^{3}$ & $6.770 \mathrm{~g} / \mathrm{cm}^{3}$ \\
\hline 2 & Molar Mass & $59.96 \mathrm{~g} / \mathrm{mol}$ & $140.12 \mathrm{~g} / \mathrm{mol}$ \\
\hline 3 & Melting Point & $1600^{\circ} \mathrm{C}$ & $798^{\circ} \mathrm{C}$ \\
\hline 4 & Boiling Point & $2230^{\circ} \mathrm{C}$ & $3424^{\circ} \mathrm{C}$ \\
\hline 5 & Particle size & $40 \mathrm{~nm}$ & $25 \mathrm{~nm}$ \\
\hline
\end{tabular}

\section{B. Preparation of Nano-materials}

Hybrid Nano-material is being synthesized by sol-gel process. Nano-silica (NS) synthesized by sol gel process is being loaded with another Nano-cerium by calcination process. 13grams of synthesized Nano-silica (NS) is being mixed with solution obtained by mixing $2.9 \mathrm{~g}$ of cerium with $43 \mathrm{ml}$ of distilled water. The obtained solution is then mixed with Nano- silica and stirred thoroughly until it reaches in the form of gel. The gel is then heated in hot air oven with a gradual increase in temperature until it reaches $500^{\circ} \mathrm{C}$ and the temperature is maintained constant for about 5 hours. Resulting product is the synthesized hybrid Nano-material to be used in the manufacture of cement mortar.

\section{Parametric study on Hybrid Nano materials}

Various parametric studies such as Pore Volume analysis, Infra-red analysis and SEM analysis were performed on hybrid Nano-material to study its physical and micro structural properties. Pore volume analysis was done to evaluate the amount of cerium to be loaded on silica to act as a hybrid Nano-material. Infra-red Analysis was done to evaluate the extent of influence of carbon on silica compounds during the hybridization. Finally synthesized Nano-particles were examined under Scanning Electron Microscope to study the extent of cerium loaded on with silica particle

\section{Mix Proportions}

Mortar Mix Proportions of $1: 3$ with w/b ratio of 0.45 was adopted for this study. A total of 80 specimens were prepared based on mix combinations to study its strength and durability properties. Hybrid Nano-materials were added at a percentage of $3 \%, 5 \%, 7 \%$ and $9 \%$ by weight of cement. Cube moulds of size $70.6 \mathrm{~mm} \times 70.6 \mathrm{~mm} \times 70.6 \mathrm{~mm}$ and cylinder moulds of size $100 \mathrm{~mm} \times 200 \mathrm{~mm}$ were fabricated to study the mechanical properties. Quantification of mix proportions to prepare mortar specimens is presented in the table II.

Table- II: Mix Proportions

\begin{tabular}{|l|l|}
\hline Mix ratio & $1: 3$ \\
\hline w/c ratio & 0.45 \\
\hline Weight of Cement & $210 \mathrm{~g}$ \\
\hline Weight of Fine Aggregate & $630 \mathrm{~g}$ \\
\hline Percentage of Cerium loaded on Silica & $5 \%$ \\
\hline
\end{tabular}

\section{E. Testing of Mortar specimens}

Material Property study such as setting time test for cement, fineness test on aggregate, specific gravity of cement and specific gravity of fine aggregate was conducted as per codal provisions and presented in table III. Various hardened property tests conducted on mortar specimens include compressive strength on mortar cubes (70.6mmx70.6mmx70.6mm) and Split tensile strength on cylinders $(100 \mathrm{mmx} 200 \mathrm{~mm})$ as per IS 10080:1982 [13]. Strength of mortar specimens was performed to study the hardened property as per IS 4031[14].

Table- III: Mix Proportions

\begin{tabular}{|c|c|c|}
\hline S. No & Property & Values \\
\hline 1 & Setting time test & 30 minutes \\
\hline 2 & Specific gravity of cement & 3.15 \\
\hline 3 & Specific gravity of fine aggregate & 2.76 \\
\hline 4 & Fineness modulus of aggregate & 3.43 \\
\hline
\end{tabular}

\section{RESULTS AND DISCUSSIONS}

\section{A. Property Study on Hybrid Nano materials}

Pore volume analysis was done on Nano-silica to check the optimum level of water to load the cerium particles on Nano- silica particles to behave as a hybrid Nano-material. Based on various trials, the optimum level of water to load cerium on Nano-silica is $3.5 \mathrm{ml}$ which is presented in table IV. Similarly from the infrared analysis the content of carbon is 1384.89 , content of silica is 1083.99 and content of cerium is 3431.36 which is shown in the fig. 1 . It could be inferred clearly that content of carbon and silica is lesser compared to cerium which is loaded over the silica particles. This attributes to the complete hybridization of cerium over silica particles. SEM analysis of hybrid Nano-particles under various scales of magnification $1 \mu \mathrm{m}, 2 \mu \mathrm{m}$ and $200 \mathrm{~nm}$ is shown in the fig.2. Images interpret the uniform loading the cerium over silica particles as the rate of magnification increases. Black solid mass in the image represents the silica particles where the white spherical particle represents the cerium particles. At $2 \mu \mathrm{m}$ magnification, it could be seen the agglomeration of cerium particles and silica particles and at $200 \mathrm{~nm}$ the complete loading of cerium particles over the silica particles was observed.

Table- IV: Mix Proportions

\begin{tabular}{|c|c|c|}
\hline Trial & Silica $(\mathbf{g})$ & Water $(\mathbf{m l})$ \\
\hline 1 & 1 & 3.2 \\
\hline 2 & 1 & 3.4 \\
\hline 3 & 1 & 3.5 \\
\hline 4 & 1 & 3.5 \\
\hline
\end{tabular}

Published By: 


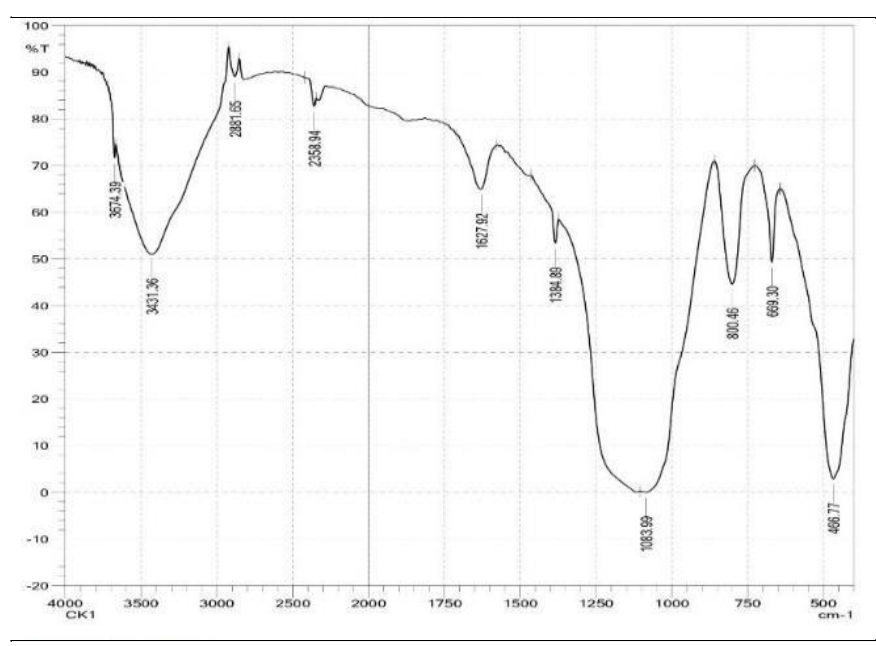

Fig.1.Infra-red Analysis

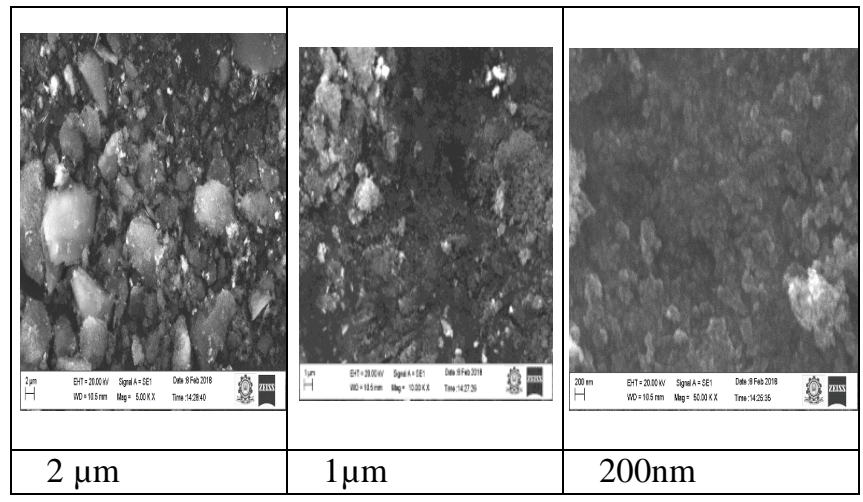

Fig.2.SEM Analysis

\section{B. Effect of HN on setting property of mortar}

Setting time test performed under different percentages of addition of $\mathrm{HN}$ is presented in the fig. 3. From the results it could be found that as the percentage of $\mathrm{HN}$ increases, setting time also increases. Maximum setting time of 69 minutes was achieved upon $10 \%$ of addition of $\mathrm{HN}$ in cement mortar. This is found to be nearly 2.5 times higher compared to the setting time of conventional mortars. This attribute is due to the accumulation of $\mathrm{HN}$ in the voids between cement particles which prolongs the setting time of the mortar.

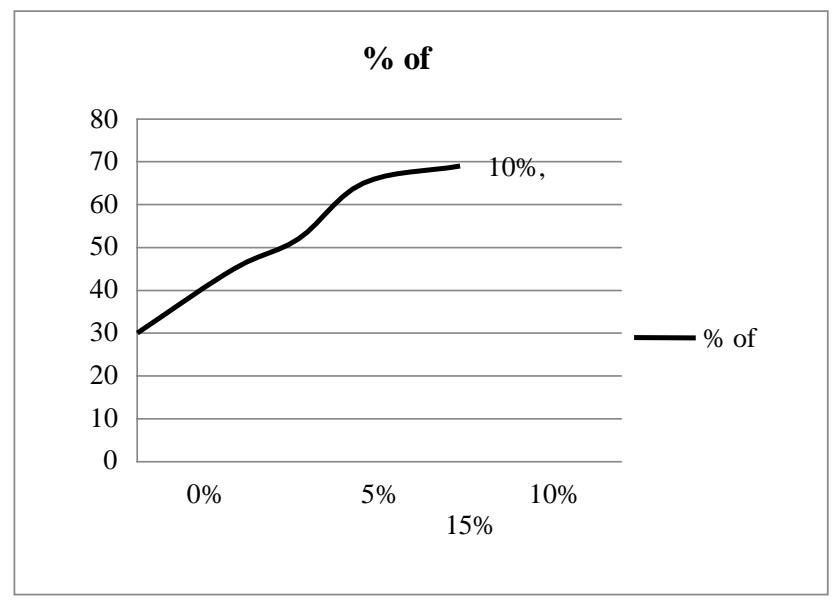

Fig.3. Influence of HN on setting on cement mortar
C. Effect of HN on compressive strength of mortar Compressive strength of mortar with $\mathrm{HN}$ under all percentages at the age of 7 days and 28 days is presented in the fig.4. From the results it is evident that compressive strength of $\mathrm{HN}$ is found to be $74.63 \mathrm{MPa}$ at the age of 28 days which is $55 \%$ more compared to compressive strength of conventional mortar. Similarly at the age of 28 days, compressive strength of $\mathrm{HN}$ is found to be $20 \%$ more compared to compressive strength of NS. On the other hand, compressive strength of NS is found to be $44 \%$ more compared to conventional mortar. Among the conventional mortar, NS and HN, mortar with $10 \%$ of HN shows higher compressive strength. This is due to the size of Nanoparticles that accumulates the voids in the paste, thereby increasing the strength of mortar. With respect to Nano-silica, the increase in the strength is not only due to its pore filling property but also promoting the formation of $\mathrm{C}-\mathrm{S}-\mathrm{H}$ with increase in the rate of hydration. Improvement is compressive strength is found to be consistent with the previous studies [10].

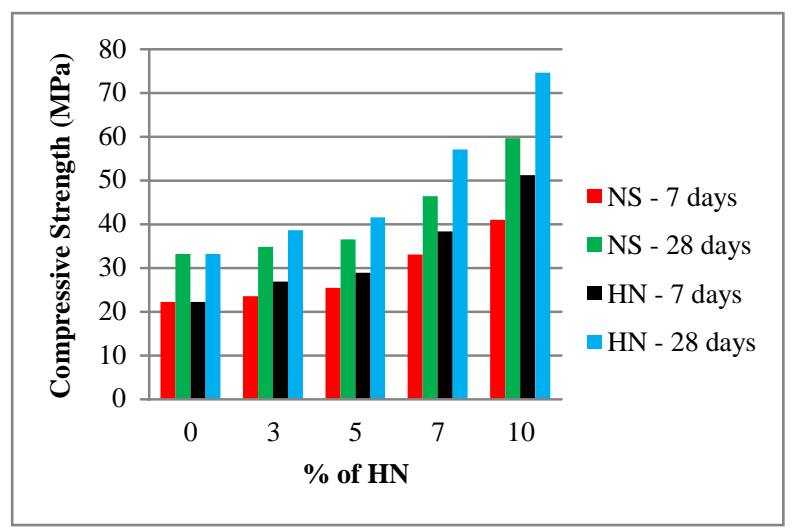

Fig.4. Compressive Strength at the age of 7 and 28 days

\section{Effect of $\mathbf{H N}$ on split tensile strength of mortar}

Split tensile strength of mortar with HN under all percentages at the age of 7 days and 28 days is presented in the fig.5. From the results it is evident that compressive strength of $\mathrm{HN}$ is found to be $5.16 \mathrm{MPa}$ at the age of 28 days which is $50 \%$ more compared to strength of conventional mortar. Similarly at the age of 28 days, compressive strength of $\mathrm{HN}$ is found to be $15.3 \%$ more compared to strength of NS. On the other hand, strength of NS is found to be $41 \%$ more compared to conventional mortar. Among the conventional mortar, NS and $\mathrm{HN}$, mortar with $10 \%$ of $\mathrm{HN}$ shows higher split tensile strength. This is due to the size of Nano-particles that accumulates the voids in the paste, thereby increasing the strength of mortar. With respect to Nano-silica, the increase in the strength is not only due to its pore filling property but also promoting the formation of $\mathrm{C}-\mathrm{S}-\mathrm{H}$ with increase rate of hydration. Improvement is split tensile strength is found to be consistent with previous studies [10]. 


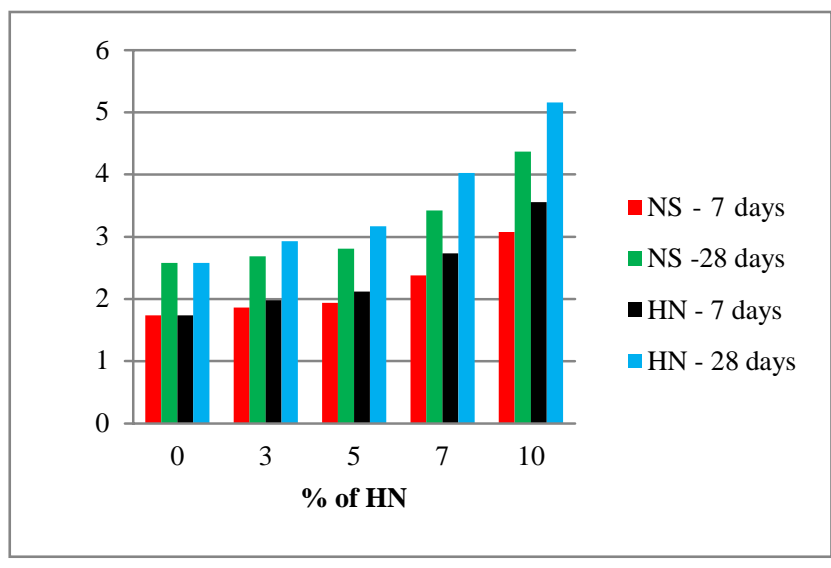

Fig.5.Split tensile Strength at the age of 7 and 28 days

\section{CONCLUSION}

This study presented the effect of hybrid Nano-material (Nano-silica loaded with cerium) on strength property of cement mortar at addition of 3\%, 5\%, $7 \%$ and $10 \%$ by weight of cement. The following conclusions were arrived:

1. Pore Volume analysis results show that around $3.3 \mathrm{ml}$ of water is sufficient to form gel so that the pores around them get clogged. Such interpretation was useful in analyzing the amount of cerium particles to be loaded over Silica particles. This in turn reduces the probability of entry of cerium in between two Nano- silica particles.

2. From the infra-red graph, the content of carbon is around 1384.89 , content of silica is around 1083.99 and content of Cerium is around 3431.36. Oxide particles of silica are more susceptible to carbon. From the results it is clear that the carbon content is very less and the concentration of Cerium is more so that the particles get easily loaded on the Silica.

3. Setting time analysis shows that the setting time value of hybrid Nano-materials are more compared to Nano-silica and conventional mortar, also as the percentage of hybrid Nanomaterial increases, the setting time of cement mortar increases. This is because of the accumulation of Nano-particles in the voids in between the cement particles. 4. Strength of hybrid Nano-material is more compared to Nano- silica as well as conventional mortar. This improvement in strength could be observed from the 7th day itself. Such attribute is due to the filler effect of Nano-silica which densifies the cement paste as well as Interfacial Transition Zone (ITZ). This rather prevents the further penetration of water due to the hybrid Nano-materials prepared based on pore volume method.

In contrast with other research works in the arena with lesser NS and HN dosage, strength of cement mortar is found to be much higher as the percentages of Nano-materials were increased. Criticality lies in the optimum level on loading of Nano-materials to clog the voids between the cement particles.

\section{REFERENCES}

1. D. Hongjian, D. Suhuan, L. Xuemei, "Durability performances of concrete with Nano-silica" Construction and Building Materials, vol. 73, Aug. 2014, pp. 705-712.

2. Z.S. Metaxa, J.W.T. Seo, M.S. Konsta-Gdoutos, MC. Hersam, SP. Shah, "Highly concentrated carbon Nano-tube admixture for Nano-fibre reinforcement cementitious materials" Cement and Concrete Composites., vol. 34, April. 2012, pp. 612-617.
3. A. Cwirzen, K. Habermehl-Cwirzen, "The effect of carbon Nano and microfibers on strength and residual cumulative strains of mortars subjected to freeze- thaw cycles" Advanced Concrete Technology., vol. 11, October. 2013, pp. 80-88.

4. H. Du, H. Gao, S.D. Pang, "Use of 2-D Nano-particles to enhance the concrete resistance to chloride ingress" in XIII International conference on durability of building materials and components, Sao Paulo, Brazil, 2014, pp. 936- 943.

5. C. Arnon, R. Rattiyakorn, N. Thanongsak, "The effect of carbon Nanotubes and silica fume on compressive strength and flexural strength of cement mortars" Materials today: Proceedings., vol. 4, Feb. 2017, pp. 6065-6071.

6. M. Baoguo, L. Hainan, L. Xiangguo, M. Junpeng, L. Yang, "Influence of Nano-TiO2 on physical and hydration characteristics of fly ash-cement systems" Construction and Building Materials, vol. 122, Mar. 2016, pp. 242-253.

7. H. Ohamed and N.S. Ibrahim, "Hydration, microstructure and phase composition of composite cements containing Nano-clay" Construction and Building Materials, vol. 112, Aug. 2016, pp. 19-27.

8. M.A. Kafi, N. Aref Sadeghi, B. Ali, N. Adel Sadeghi, and M. Ebrahim, "Micro structural Characterization and Mechanical Properties of Cementitious Mortar Containing Montmorillonite Nano particles" Journal of Materials in Civil Engineering, vol. 28, Dec. 2016, pp. 67-77.

9. M.S. Morsy, Y.A. Al-Salloum, H. Abbas, S.H. Alsayed, "Behaviour of blended cement mortars containing Nano-Metakolin at elevated temperatures" Construction and Building Materials, vol. 35, Dec. 2012, pp. 900-905.

10. J. Byung-Wan, K. Chang-Hyun, T. Ghi-ho, P. Jong-Bin, "Characteristics of cement mortar with Nano-SiO2 particles" Construction and Building Materials, vol. 21, Sep. 2007, pp. 45-56.

11. K.L. Lin, W.C. Chang, D.F. Lin, H.L. Luo, M.C. Tsai, "Effects of Nano- $\mathrm{SiO} 2$ and different ash particle sizes on sludge ash-cement mortar" Journal of Environmental Management, vol. 88, Aug. 2008, pp. 708-714.

12. L.G. Li, J. Zhu, Z.H. Huang, A.K.H. Kwan, L.J. Li, "Combined effects of micro-silica and Nano-silica on durability of mortar" Construction materials, vol. 157, July. 2017, pp. 337-347.

13. IS 10080 (1982): Method of test split tensile strength of mortar

14. IS 4031-4 (1988): Method of physical test of hydraulic cement

\section{AUTHORS PROFILE}

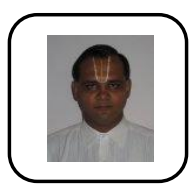

Dr. T.R. Neelakantan, is a Senior Professor in Civil Engineering and Director - Accreditation and Ranking at Kalasalingam Academy of Research and Education, Tamilnadu. He obtained his Ph.D. degree in Civil Engineering from Anna University in the year 1998. His working experiences are from Anna University, IIT-Madras, SASTRA Deemed University and the University of Kentucky, Lexington, USA. He published more than 60 articles in reputed journals, and handled many government and private funded projects both in India and USA.

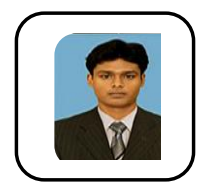

Jagan Sivamani, completed M. Tech in Structural Engineering from VIT University in 2015, B.Tech in Civil Engineering from Kongu Engineering College in 2013. I am currently working as Assistant Professor at Kalasalingam Academy of Research and Education. During my career I have published my research worked in 8reputed International Journals and also attended many International conferences, workshops and seminars. Also, a life member of IAENG association. 